\title{
Quality control in colorectal cancer screening: Systematic microbiological investigation of endoscopes used in the NORCCAP (Norwegian Colorectal Cancer Prevention) trial Michael Bretthauer*1, Anita Jørgensen², Bjørn Erik Kristiansen ${ }^{3}$, Bjørn Hofstad ${ }^{4}$ and Geir Hoff ${ }^{5}$
}

Address: ${ }^{T}$ The Cancer Registry of Norway, 0310 Oslo, Norway, ${ }^{2}$ Department of Gastroenterology, Telemark Hospital, 3710 Skien, Norway, ${ }^{3}$ Telelab as, 3710 Skien, Norway, ${ }^{4}$ Department of Gastroenterology, Ullevaal University Hospital, 0407 Oslo, Norway and ${ }^{5}$ The Cancer Registry of Norway, 0310 Oslo, Norway

Email: Michael Bretthauer* - michael.bretthauer@sthf.no; Anita Jørgensen - anita.jorgensen@sthf.no;

Bjørn Erik Kristiansen - bjorn.erik.kristiansen@telelab.no; Bjørn Hofstad - bjorn.hofstad@ioks.uio.no; Geir Hoff - hofg@online.no

* Corresponding author

Published: 13 June 2003

BMC Gastroenterology 2003, 3:15
Received: 07 April 2003

Accepted: I3 June 2003

This article is available from: http://www.biomedcentral.com/I47I-230X/3/I5

(C) 2003 Bretthauer et al; licensee BioMed Central Ltd. This is an Open Access article: verbatim copying and redistribution of this article are permitted in all media for any purpose, provided this notice is preserved along with the article's original URL.

\begin{abstract}
Background: Endoscopic colorectal cancer (CRC) screening is currently implemented in many countries. Since endoscopes cannot be sterilised, the transmission of infectious agents through endoscopes has been a matter of concern. We report on a continuous quality control programme in a large-scale randomised controlled trial on flexible sigmoidoscopy screening of an average-risk population. Continuously, throughout a two-year screening period, series of microbiological samples were taken from cleaned ready-to-use endoscopes and cultured for bacterial growth.
\end{abstract}

Results: 8573 endoscopies were performed during the trial period. Altogether, 178 microbiological samples $(2 \%)$ were taken from the biopsy channels and surfaces from the endoscopes. One sample (0.5\%) showed faecal contamination (Enterobacter cloacae), and 25 samples (14\%) showed growth of environmental bacteria.

Conclusions: Growth of bacteria occurs in a clinical significant number of samples from ready-touse endoscopes. Pathogenic bacteria, however, were found only in one sample. Improvement of equipment design and cleaning procedures are desirable and continuous microbiological surveillance of endoscopes used in CRC screening is recommended.

\section{Background}

Colorectal cancer (CRC) is a major cause of personal suffering and death in the developed world. Screening for CRC by gastrointestinal endoscopy (flexible sigmoidoscopy or colonoscopy) has been recommended for the average-risk population [1], and is currently implemented in many Western countries. For the time being, endoscopes commonly used for diagnostic and therapeutic as well as for CRC screening purposes, are reusable tools. The endoscopes have to be cleaned manually and/or by using washing machines especially designed for this purpose [2]. The design and material of the endoscopes do not allow sterilisation. Cleaning and disinfection of the devices has been a subject of concern, as transmission of infectious material cannot be entirely dismissed [3]. In 2002, the New York Times reported on the possible transmission of Pseudomonas infection to 400 patients after examination with bronchoscopes that were not 
adequately designed to ensure proper cleansing and disinfection [4]. Only most recently, outbreaks of bacterial infection associated with flexible bronchoscopes have been confirmed $[5,6]$. In a multicentre trial in Germany bacterial growth was found in $49 \%$ of cleaned endoscopes, and inadequate cleaning facilities and/or routines were found in more than $50 \%$ of endocopy centres [7].

According to current WHO guidelines, all screening tests should be designed to ensure that the test itself does not cause any harm to screenees. Substantial efforts should therefore be made to minimize any risk of contamination of endoscopes. This is especially important in CRC screening where presumptively healthy individuals are exposed to endoscopy.

NORCCAP is a large-scale randomized controlled trial for CRC prevention by flexible sigmoidoscopy (FS). Twentyone thousand individuals, age 50-64 years, were randomly drawn from the Norwegian Population Registry and invited to an FS screening examination [8]. Screening was performed between 1999 and 2001 at two centres in South East Norway. As part of a continuous quality control programme in the NORCCAP trial, microbiological samples were systematically taken from cleaned endoscopes throughout the trial. The aim of the present study was to investigate the quality of cleaning of endoscopes used in CRC screening.

\section{Results}

During the 2-year study period, 8573 examinations were performed (3798 at centre I, 4775 at centre II). One hundred and seventy eight samples ( $2 \%$ of 8573 ) were taken for microbiological investigation.

Bacterial growth was observed in 16 out of 107 (15\%) samples from the biopsy channels and in 10 out of 71 (14\%) samples from the endoscope surface. At centre I, we observed growth in 7 out of 41 biopsy channel samples $(17 \%)$, and in 3 out of $35(9 \%)$ surface samples. At centre II, 9 out of $66(14 \%)$ samples from the biopsy channel and 7 out of $36(19 \%)$ surface samples showed bacterial contamination. One sample (at centre I) showed growth of Enterobacter cloacae, indicating faecal contamination. This endoscope was re-tested after two weeks without any findings of contamination. The other bacteria found were low- or non-virulent species of the environment:

- Staphylococcus epidermidis in 8 biopsy channel samples and 7 surface samples

- Micrococci in 2 biopsy channel samples and 3 surface samples
- Bacillus sp. in 3 biopsy channel samples

- Pseudomonas stutzeri in 1 biopsy channel sample

- Weeksella virosa in 1 biopsy channel sample

\section{Discussion}

Also after cleaning and disinfection adhering to current guidelines [2], a considerable number of microbiological samples taken from cleaned ready-to-use endoscopes showed bacterial growth. The vast majority of microbes found were environmental bacteria. In one out of 178 samples $(0.5 \%)$, however, Enterobacter cloacae was found, indicating faecal contamination of the endoscope. We did not search for any viruses or Mycobacteria in the present trial. However, the finding of faecal bacteria is an indicator for other pathogenic organisms potentially present in that particular endoscope. In a recent study on Helicobacter pylori contamination of gastroscopes, the authors report on one contamination out of 128 samples of manually cleaned endoscopes [11].

Our results show that the risk of transmission of infections by endoscopy is real, but probably small when following current cleaning guidelines and using endoscope washing machines. Continuous microbiological investigation of endoscopes should be performed in any CRC screening programme. After the finding of enterobacteria in one of our endoscopes, we improved the cleaning process by adding a detergent solution to the tap water used for flushing the biopsy channel by suction immediately after each endoscopy procedure, to destroy any debris or biofilm containing microorganisms. This procedure is recommended in the ESGE guidelines [2], but is not common practice in Norway.

Additionally, we started rinsing the biopsy channels of all endoscopes with alcohol at the end of each session, to improve the drying of the inner surfaces. This procedure is additional to the cleaning and disinfection procedures currently recommended by the ESGE. However, this measure is mentioned as an add-on procedure in a 1992 working party report by the British Society of Gastroenterology Endoscopy Committee [9]. Surprisingly, a similar recommendation is also found in a former version of the ESGE guidelines (published in 1995) [10]. In the current version, for some reason, this paragraph has been deleted [2]. In the light of the present study, it might be re-incorporated in future ESGE guidelines. However, it is not clear whether contamination of endoscopes in our trial was due to inappropriate procedures or individual failure to adhere to the procedures. 
Table I: Comparison of the cleaning and disinfection procedures recommended by the European Society for Gastrointetsinal Endoscopy (ESGE) [2] and those used in the present trial.

\begin{tabular}{lll}
\hline & \multicolumn{1}{c}{ ESGE guidelines } & \multicolumn{1}{c}{ Policy in the present trial } \\
\hline I. Manual cleaning & $\begin{array}{l}\text { - Flushing air/water channel with water } \\
\text { - Immersion in water and detergent, external cleaning } \\
\text { and brushing/rinsing of instrument channels } \\
\text { - Flushing air/water channel with detergent (facultative) }\end{array}$ & $\begin{array}{l}\text { - Flushing air/water channel with water } \\
\text { - Immersion in water and detergent, external cleaning } \\
\text { and brushing/rinsing of instrument channels }\end{array}$ \\
$\begin{array}{ll}\text { - Flushing air/water channel with detergent* } \\
\text { 2. Automatic disinfection }\end{array}$ & $\begin{array}{l}\text { - Washing, disinfection and drying according to the } \\
\text { manufacturer specification }\end{array}$ & $\begin{array}{l}\text { - Washing, disinfection and drying according to the } \\
\text { manufacturer specification }\end{array}$ \\
3. Before storage & - & - Flushing biopsy channel with 70\% alcohol*
\end{tabular}

*Comprehensive procedures, incorporated in local policy after finding of Enterobacter cloacae in one endoscope.

\section{Conclusions}

In the present study, growth of bacteria was observed in a significant number of samples from endoscopes cleaned in accordance to current guidelines. Pathogenic bacteria, however, were found only in one out of 178 samples. Transmission of infectious agents through endoscopes cannot be excluded. Systematic microbiological investigation of endoscopes is recommended, especially in CRC screening, exposing presumptively healthy individuals to potentially infectious material. For the future, endoscopes with disposable sheaths, providing every screenee with a sterile endoscope may be desirable to prevent transmission of infectious agents $[3,12]$.

\section{Methods}

\section{Type of endoscopes used}

Video colonoscopes (CF-VI and CF 140, Olympus Europa, Hamburg, Germany) were used for all examinations. Generally, at each of the two centres, seven endoscopes were available. Occasionally, however, endoscopes have been away for service or repairs.

\section{Cleaning and disinfection of endoscopes}

Cleaning personal consisted on four endoscopy assistants at each centre. Before the start of the trial, all cleaning staff was trained practically and theoretically, including two weeks of training at a certified endoscopy lab, and a oneday course on endoscopy cleaning procedures. Additionally, written methods on the cleaning and disinfection procedures have been made available for all employees. Our cleaning and disinfection policy followed current guidelines by the European Society of Gastrointestinal Endoscopy (ESGE) [2], table 1.

For cleaning and disinfection of endoscopes, automatic washer-disinfectors (ETD-2 plus, Olympus Europa, Hamburg, Germany) were used according to the manufacturer's specifications, after first using tap water flushing of the air/water channel, and manual surface cleaning and brushing of biopsy channels, adhering to current guidelines [2]. After the finding of Enterobacter cloacae in one of our endoscopes, we extended our policy by two additional procedures (table 1):

1. Adding a detergent solution (3-E zyme, Medisafe, Herfordshire, UK) to the tap water used for flushing the biopsy channel immediately after each endoscopy procedure. This is recommended as a facultative add-on procedure in the ESGE guidelines [2].

2. Rinsing of the biopsy channels with $70 \%$ alcohol at the end of each session. This procedure is not mentioned in the current ESGE guidelines [2], but is recommended as add-on in a former version of the ESGE guidelines, and in guidelines of the British Society of Gastroenterology $[9,10]$.

There were no differences between the two NORCCAP screening centres regarding the type of endoscopes used and the cleaning and disinfection routines.

\section{Microbiological sampling}

Microbiological samples from all available NORCCAP endoscopes were taken at eight different Monday mornings throughout a 2-year screening period, the endoscopes not having been used or cleaned after the preceding Friday session. The dates of sampling were chosen randomly by the heads of the NORCCAP trial and thescreening centres. All endoscopes available at the respective centres on the day chosen were examined in the following way: samples were taken from both the tip of the endoscopes, and from sterile water flushings through the biopsy channels of the endoscopes. The samples from the endoscope surface were cultured by pressing the surface of the endoscopes onto McConkey and CLED medium present on the commercially available Uricult dip-slide system (Orion Diagnostica, Espoo, Finland) originally designed to grow bacteria from urine. The biopsy channels were flushed with sterile saline which was subsequently applied to both blood agar and CLED agar plates. The dip-slides and the plates were grown at $37^{\circ} \mathrm{C}$. Any growth of microorganisms was identified according to standard procedures. The 
laboratory performing the sampling and identification of microorganisms is an independent laboratory, not connected to the NORCCAP trial in any way.

The study was part of the NORCCAP trial. The NORCCAP protocol has been approved by the regional ethics committee. Written informed consent was given by all NORRCAP participants before entering the trial.

\section{Competing interests}

None declared.

\section{Authors' contributions}

Michael Bretthauer is the corresponding author of the study. He took part in designing the study, performed the data analyses and drafted the manuscript.

Anita Jørgensen co-designed the study, organised the data sampling at one of the screening centres, and gave critical comments to the manuscript.

Bjørn Erik Kristiansen co-designed the study, was responsible for the microbiological investigation of the samples collected, and co-drafted the manuscript.

Bjørn Hofstad organised the data sampling at one of the screening centres, and gave critical comments to the manuscript.

Geir Hoff had the idea and designed the study. He supervised the sampling of data at the screening centres, and codrafted the manuscript.

All authors read and approved the final version of the manuscript.

\section{References}

I. Rex D, Johnson DA, Lieberman DA, Burt RW and Sonnenberg A: Colorectal cancer prevention 2000: Screening recommendations of the American College of Gastroenterology. Am J Gastroent 2000, 95:868-877.

2. Guidelines on cleaning and disinfection in GI endoscopy. The European society of gastrointestinal endoscopy. [http:// www.esge.com/guidelines/cleaning and disifnection 1999.php]

3. Rex D, Atkin W, Hoff G and Waye J: The flexible sigmoidoscope. Report of the flexible sigmoidoscopy subcommittee of the OMED colorectal cancer screening committee. Gastrointest Endosc 2000, 52:587-589.

4. Altman LK and Grady D: Hospital says faulty recall may have exposed 400 to infection. NY Times. March 52002

5. Kirschke DL, Jones TF, Craig AS, Chu PS, Mayernick GG, Patel JA and Schaffner W: Pseudomonas aeruginosea and serratia marcescens contamination associated with a manufacturing defect in bronchoscopes. N Engl J Med 2003, 348:2 I4-220.

6. Srinivasan A, Wofenden LL, Song XL, Mackie K, Hartsell TL, Jones HD, Diette GB, Orens JB, Yung RC, Ross TL, Merz W, Scheel PJ, Haponik EF and Perl TM: An outbreak of pseudomonas aeruginosa infections associated with flexible bronchoscopes. $N$ Engl J Med 2003, 348:22I-227.

7. Bader L, Blumenstock $G$ and Birkner B: Hygea (hygiene in der gastroenterologie-endoskop-aubereitung): studie zur qualitat der aubereitung von flexiblen endoskopen in klinik und praxis. Z Gastroenterol 2002, 40: 157- 170.

8. Bretthauer M, Gondal G, Larsen IK, Carlsen E, Eide TJ, Grotmol T, Skovlund E, Vatn MH and Hoff G: Design, organization and management of a controlled population screening study for detection of colorectal neoplasia. Attendance rates in the NORCCAP study (Norwegian Colorectal Cancer Prevention). Scand J Gastroenterol 2002, 37:568-573.

9. Cleaning and disinfection of equipment for gastrointestinal endoscopy. Report of a working party of the British society of gastroenterology endoscopy committee: British society of gastroenterology endoscopy committee. Gut 1998, 42:585-593.

10. European society of gastrointestinal endoscopy: Endoscopic guidelines, second edition. Endoscopy 1995, 27:I-II.

II. Nurnberg M, Schulz HJ, Ruden $\mathrm{H}$ and Vogt K: Do conventional cleaning and disinfection techniques avoid the risk of endoscopic helicobacter pylori transmission? Endoscopy 2003, 35:295-299.

12. Bretthauer M, Hoff G, Thiis-Evensen E, Grotmol T, Larsen IK, Kjellevold $\varnothing$ and Skovlund E: Use of a Disposable Sheath System for Flexible Sigmoidoscopy in Decentralized Colorectal Cancer Screening. Endoscopy 2002, 34:8|4-8I8.

\section{Pre-publication history}

The pre-publication history for this paper can be accessed here:

http://www.biomedcentral.com/1471-230X/3/15/prepub
Publish with Bio Med Central and every scientist can read your work free of charge

"BioMed Central will be the most significant development for disseminating the results of biomedical research in our lifetime. "

Sir Paul Nurse, Cancer Research UK

Your research papers will be:

- available free of charge to the entire biomedical community

- peer reviewed and published immediately upon acceptance

- cited in PubMed and archived on PubMed Central

- yours - you keep the copyright
BioMedcentral 